\title{
Assessments of Functioning in Patients With Axial Spondyloarthritis
}

\author{
Uta Kiltz, M.D., Jürgen Braun, M.D. \\ Rheumazentrum Ruhrgebiet and Ruhr-University Bochum, Herne, Germany
}

\begin{abstract}
A standardized assessment of functioning in patients with axial spondyloarthritis (axSpA) is necessary in order to assess clinical manifestations, disease activity, and physical and overall functioning as objectively as possible. The standardized assessment is based on domains such as disease activity, quality of life, functioning and employment but also on individual aspects such as pain, arthritis and enthesitis. Domains and individual aspects are mainly collected and better known as patient reported outcomes. (J Rheum Dis 2020;27:22-29)
\end{abstract}

Key Words. Axial spondylitis, Assessment, Function

\section{INTRODUCTION}

The term spondyloarthritis $(\mathrm{SpA})$ comprises a partially heterogeneous group of rheumatic diseases that have some characteristic features in common: in addition to inflammation in the axial skeleton (sacroiliitis, spondylitis), inflammation of peripheral joints (arthritis) and tendon insertions (enthesitis) does also frequently occur [1]. In the long-term syndesmophytes and ankylosis dominate the clinical picture (mainly but not only in patients with persistent inflammation). Thus, limited mobility of the spine is pathognomonic for patients with axial SpA (axSpA), especially in advanced stages of ankylosing spondylitis (AS). This historically established term is almost synonymous with the subgroup radiographic axSpA ( $r$-axSpA), which, for classification purposes, can be differentiated from non-radiographic axSpA (nr-axSpA) [2,3]. The main distinguishing feature between $\mathrm{r}$-axSpA and $\mathrm{nr}$-axSpA is the presence of definitive structural changes in the sacroiliac joints according to the $1984 \mathrm{NY}$ criteria [4]. The disease burden was shown to be similar in patients with r-axSpA and nr-axSpA [5] but there are also some important differences related to inflammation and new bone formation [6].

Patients with axSpA suffer from pain, functional disability, especially spinal stiffness, sleep problems, fatigue and limitation in activities and social participation [7] which has a strong impact on patient-reported outcomes and health related quality of life measures. In addition, socio-economic aspects such as education, employment, and economic status are affected by axSpA. Functional disability is a major contributor to the disease burden of axSpA. Compared with patients of other medical conditions, axSpA patients have low scores in the physical domains of generic instruments such as the short-form36 (SF-36) (2. Compund measures) [8]. It has been shown that longer disease duration and increasing age are associated with decreased functioning, whereas performing back exercises and having a greater degree of social support improved functioning [9]. The level of pain has a considerable influence on health-related quality of life (HRQoL) in axSpA. As many as $83 \%$ of axSpA patients report problems with pain, and for one third it is of critical importance [7]. Female patients are 2 to 3 times more likely than men to have greater pain levels. Fatigue, an important symptom in axSpA, is reported by $67 \%$ of patients

\footnotetext{
Received : December 9, 2019, Revised : December 9, 2019, Accepted : December 10, 2019

Corresponding to : Uta Kiltz (D)http://orcid.org/0000-0001-5668-4497

Rheumazentrum Ruhrgebiet and Ruhr-University Bochum, Claudiusstr 45, Herne 44649, Germany. E-mail : Uta.kiltz@elisabethgruppe.de

Copyright (c) 2020 by The Korean College of Rheumatology. All rights reserved.

This is an Open Access article, which permits unrestricted non-commerical use, distribution, and reproduction in any medium, provided the original work is properly cited.
} 
[10]. Although the physical aspects of health seem to be most severely affected, the disease impact on mental health is also considerable. Cohort studies showed that almost half of the patients with axSpA had a high risk for depression and anxiety $[11,12]$. Of interest, the level of disease activity in axSpA does correlate significantly with anxiety and depression.

Work loss is one of the most important outcomes in chronic inflammatory rheumatic diseases. Employment rates are $11 \%$ lower and work disability rates $15 \%$ higher than in the general Dutch population $[13,14]$. Furthermore, work productivity is reduced in up to $45 \%$ of patients with SpA [15]. Work status is an important determinant influencing HRQoL in patients with axSpA [16]. This of major importance in patients with low education levels [17]. Thus, special attention on this aspect is needed and appropriate patient education mandatory to support successful coping strategies.

Patient-reported outcomes are based on subjective symptoms frequently reported by axSpA patients that are not easily assessed. These symptoms play an important role in the management of patients with axSpA. Outcome parameters assessing various aspects of functioning have been developed for symptoms such as pain and enthesitis, but also for domains such as disease activity, physical and emotionial functioning as well as mobility, quality of life and social participation (Table 1).

More than two decades ago, the Assessment of Spondlyoarthritis International Society (ASAS) has published a Core Set of Outcome Parameters, which includes subjective symptoms such as pain and fatigue as well as the assessment of spinal mobility and function and radiological progression (Figure 1) [18]. The outcome parameters listed in the inner circle of the core set are considered mandatory and assessment must be done in clincical trials.

The Core set is currently being revised by ASAS in order to implement more recent findings and also to enable greater patient participation.

The aim of this article is to give an overview of the available instruments to assess various aspects of functioning in patients with axSpA. Moreover, the impact of axSpA on a wide range of HRQoL domains will be described. Since axSpA usually starts in early adulthood, the life-time impact of axSpA on HRQoL is also important. The level of HRQoL impairment in patients with axSpA was shown to be comparable to that of rheumatoid arthritis (RA) and is markedly reduced compared to the general population
$[17,19]$.

\section{MAIN SUBJECTS}

\section{Assessment of functioning \\ 1) Individual symptoms}

Individual clinical symptoms, such as general pain, global patient assessment and fatigue (bath AS disease activity index [BASDAI] Question 1) can all be recorded by use of numerical rating scales, where 0 means the best possible condition and 10 the worst possible [20]. Assessment using a visual analogue scale (VAS, often as a $0 \sim 100 \mathrm{~mm}$ variant) is also possible. Because use of VAS is more error-prone in respect to reproducibility of accurate metric results, ASAS favours usage of a numeric rating scale (NRS).

Table 1. Domains and instruments in axial spondyloarthritis

\begin{tabular}{|c|c|}
\hline Domains & Instruments \\
\hline \multicolumn{2}{|l|}{ Single domains } \\
\hline \multirow[t]{2}{*}{ Pain } & $\begin{array}{l}\text { VAS or NRS - nocturnal back } \\
\text { pain of last week due to AS }\end{array}$ \\
\hline & $\begin{array}{l}\text { VAS - Back pain of last week } \\
\text { due to AS }\end{array}$ \\
\hline Peripheral joints & $\begin{array}{l}\text { Number of swollen joints } \\
\text { (66 joints) }\end{array}$ \\
\hline Enthesitis & Mases, Sparcc, LEI \\
\hline Fatigue & $\begin{array}{l}\text { VAS or NRS - fatigue last } 7 \\
\text { days }\end{array}$ \\
\hline Global patient assessment & VAS - last week \\
\hline \multicolumn{2}{|l|}{ Composite domains } \\
\hline \multirow[t]{2}{*}{ Disease activity } & BASDAI \\
\hline & ASDAS \\
\hline \multirow{2}{*}{$\begin{array}{l}\text { Physical functioning and } \\
\text { mobility }\end{array}$} & BASMI \\
\hline & BASFI \\
\hline \multirow{4}{*}{$\begin{array}{l}\text { Quality of life and social } \\
\text { participation }\end{array}$} & SF-36 \\
\hline & EQ-5D \\
\hline & ASAS HI \\
\hline & AS-Qol \\
\hline Employment & WPAI \\
\hline
\end{tabular}

VAS: visual analogue scale, NRS: numeric rating scale, AS: ankylosing spondylitis, LEl: leeds enthesitis index, BASDAI: bath ankylosing spondylitis disease activity index, ASDAS: ankylosing spondylitis disease activity score, BASMI: bath ankylosing spondylitis metrology index, BASFI: bath ankylosing spondylitis functional index, SF-36: short-form-36, EQ-5D: Euroquol 5 dimensions, ASAS HI: Assessment of Spondlyoarthritis International Society health index, Qol: quality of life, WPAI: Work Productivity and Activity Impairment Questionnaire. 


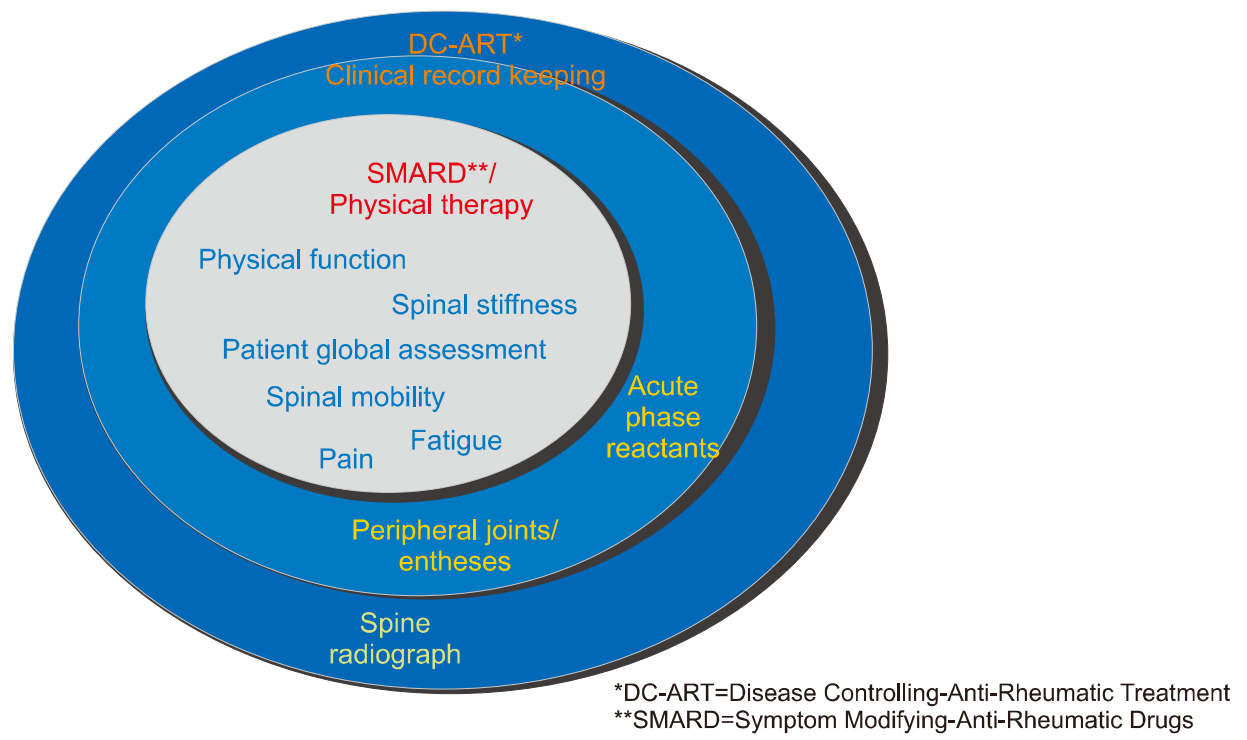

Adapted from van der Heijde D et al. J Rheumatol 1999;26:951-4 (with permission) ASAS workshop Gent, Oct 2002
Figure 1. Assessment of Spondyloarthritis International Society (ASAS)/Outcome Measures in Rheumatology Clinical Trials (OMERACT) Core Domains for ankylosing spondylitis (courtesy of www.asas-group.org).

\section{2) Compund measures}

(1) Disease activity

A number of procedures are available to record disease activity in a standardized way: Questionnaires with several questions (e.g., BASDAI [19]) or individual questions (e.g., back pain or patient global assessment), laboratory parameters (e.g., C-reactive protein [CRP]) or composite assessments (e.g., AS disease activity index [ASDAS] [20]).

BASDAI: The BASDAI is a patient self-report questionnaire which collects the disease activity on the basis of 5 domains (joint and back pain, fatigue, tenderness in the joints and morning stiffness [21]. The total of 6 questions are answered on a NRS of $0 \sim 10(0=$ no disease activity, $10=$ high disease activity). The total sum ranges between 0 (no disease activity) and 10 (high disease activity) and covers the period of the last 7 days. A BASDAI value $\geq 4$ is evaluated as high disease activity [22]. The version "miniBASDAI" with only 4 questions (questions 3 and 4 [peripheral joints and entheses]) has not been really implemented in clinical practice [23]. The BASDAI is used in clinical routine as well as in studies, this tool is well established in both settings for practical reasons. In a Dutch cohort of AS patients considerable individual variability of BASDAI values has been reported in a longterm observational study [24].

It is important to note that comorbidities can influence response pattern of individual patients. In patients with
axSpA and degenerative spinal disease, the assessment of disease activity can be overestimated by superposition of the symptom back pain due to any other cause. In patients with axSpA and fibromyalgia, the disease activity of axSpA can be much overestimated by altered pain processing. In the observational study Predict-SpA it was shown that the presence of 3 BASDAI items with extreme values (defined as $\geq 8$ ) had a high specificity for the presence of fibromyalgia [25]. Since it was shown that firbomyalgia (FM) is rather prevalent in axSpA and since this was shown to influence the response to biologic therapy, a critical evaluation of the BASDAI and use of questionnaires developed to diagnose FM American College of Rheumatology (ACR) criteria seems necessary in order to avoid inappropriate escalation of treatment [26]. To differentiate pain due to spondylitis from generalized pain due to FM can be challenging though.

In interventional studies, changes in disease activity after initiation of therapy can be assessed using a $50 \%$ improvement of BASDAI [27]. In the majority of studies, the BASDAI-50 response has been replaced by the ASAS 40 response or ASDAS major improvements, which, as composite instruments, represent the various facets of the disease in a better way.

ASDAS: The ASDAS has been developed on the basis of 3 individual BASDAI questions on back and joint complaints and morning stiffness, taking into account the current CRP value and patient global assessment of current 
disease activity [28]. The ASDAS sum value lies between 0 (no disease activity) and 10 (very strongly increased disease activity). An ASDAS value $<1.3$ represents an inactive disease, 1.3 to 2.1 a low disease activity, 2.1 and $<3.5$ a high disease activity and $\geq 3.5$ a very high disease activity (Figure 2) [29]. An improvement of ASDAS sum scores by $\geq 1.1$ or $\geq 2.0$ points is considered a clinically significant improvement (Figure 2). A significant deterioration of disease activity is defined by $\geq 0.9$ points of the ASDAS total score [30]. Although the psychometric properties of the ASDAS Score are superior to those of the BASDAI, its use is essentially limited to clinical studies and has not found its way into routine care-mainly due for feasibility reasons since CRP and ESR values are often not immediately available.

(2) Mobility and physical functioning

In patients with axSpA, physical functioning and mobility are closely related, but not identical. Under the generic term of functioning, various dimensions such as physical, emotional and social functioning are subsumed. The individual aspects of which are divided into the aspects of physical functional ability and global or social functioning for reasons of comprehensibility in this article. Mobility is the metric component of functional ability. Physical functioning is influenced both by disease activity and by structural damage and these influencing parameters should therefore also be assessed separately [28]. While functioning is usually assessed by questionnaires to be subjectively filled out by the patient, spinal mobility is actively examined by a health professional. However, functioning can also be assessed by directly measuring the actual performance of patients.

Mobility (bath ankylosing spondylitis metrology index, BASMI): The measurement of the range of motion of the spinal column is of central importance in the physical ex- amination of patients with axSpA. Reproducible valid examination techniques are established for the cervical, the thoracic and the lumbar spine (ante-, lateral- and retroflexion, rotation). The mostly used test according to the proposal of Schober is an examination of forward bending of the spinal column (measurement of a defined section of the lower lumbar spine in normal posture and after anteflexion, normal $>3 \mathrm{~cm}$ ). For short-term follow-up examinations, however, this is less sensitive than measuring the lateral flexion of the spinal column (normal $>10$ $\mathrm{cm}$ on both sides). The thoracic excursion mainly measures the mobility of the costosternal and costovertebral joints. Assessment of thorax excursion is performed in the area of the 4th intercostal range before and after maximal in- and expiration (normal $>3 \mathrm{~cm}$ ). The occiput-to-wall distance (normal $<3 \mathrm{~cm}$ ) is measured to assess kyphosis. Measurement of cervical rotation is performed using a goniometer in a position behind the seated patient (normal $>60^{\circ}$ ). In all measurements, values determined vary depending on age [31]. The examinations of spinal column mobility are recommended for monitoring the course of disease and should be carried out on a regular basis, intervals to individually determine. Active inflammation of the sacroiliac (SI) joints (e.g., by Mennel's sign) cannot be assessed on a sole clinical basis with sufficient certainty, nor can the extent and severity of the spinal infestation be determined clinically-thus, further imaging is needed.

A combined measurement tool for spinal mobility is the BASMI (which is frequently collected in clinical studies [32]. The BASMI measures mainly the spinal mobility of the patient which is composed of the lateral lumbar flexion, the tragus-wall distance, the lumbar flexion, the maximum intermalleolar distance and the cervical angle of rotation. The BASMI score is the average of the 5 in-
A

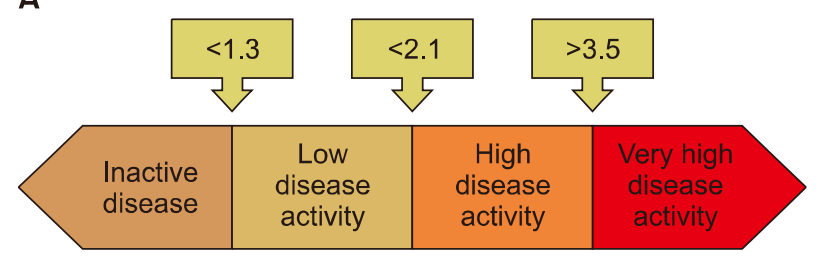

B

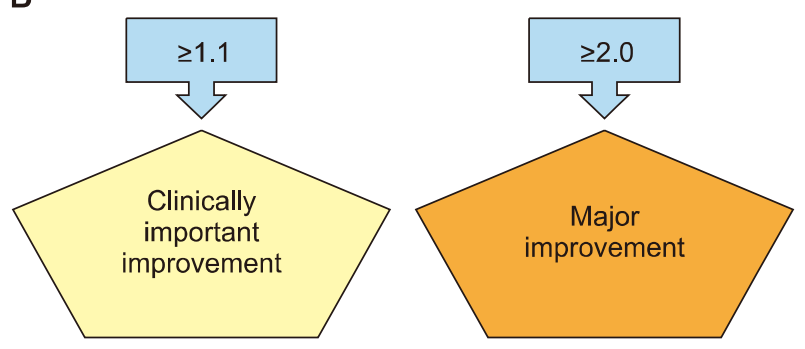

Machado P et al. Ann Rheum Dis 2011;70:47-53 (with permission)

Figure 2. ASDAS thresholds for disease status (A) and meaningful change (B) (courtsey of www.asas-group.org). 
dividual measurements. Of the three different BASMI definitions, ASAS recommends the 10 steps or the linear BASMI definition.

Bath ankylosing spondylitis functional index (BASFI): The BASFI was developed to measure physical functionality [33]. The disease-specific BASFI contains 10 questions to be filled in by the patient about everyday activities that could be performed in the last 7 days without any aids, e.g., putting on socks, picking things up from the floor or reaching a high shelf. The response options are determined using an NRS of $0 \sim 10(0=$ no restriction, $10=$ very severe restriction). A mean value is formed from the results of the 10 questions, whereby 0 means no restriction and 10 very strongly restricted physical function ability.

(3) Global functioning and HRQoL

Generic and disease-specific questionnaires have been developed to assess impairments in HRQOL. Some questionnaires rely only to the assessment of HRQoL, others address global functioning or focus on individual aspects such as activity and participation. Impairments and limitations in health are recognized to be a very important part of the construct of HRQoL. However, attributes of HRQoL are evaluated subjectively whereas impairments in global fucntioning can be assessed in a standardized manner by use of the International Classification for functioning, disability and health (ICF) published by the World Health Organization (WHO) [34,35].

In clinical studies, "SF-36" and "Euroquol 5 Dimensions" (EQ-5D) are used as generic instruments and ASAS health index (ASAS HI) are used as disease-specific questionnaires to assess global functioning or quality of life of patients with axSpA [22-25].

In recent years, focus has increasingly shifted to recording emotional symptoms such as anxiety or depressive symptoms. Although depressive symptoms are included in many questionnaires on health status and quality of life, they are often not considered as individual items. A large number of different questionnaires are suitable for screening-although none of these questionnaires are particularly recommended for patients with axSpA. Questionnaires like Hospital Anxiety and Depression Scale (HADS), Patient Health Questionnaire 9 Questions (PHQ 9) or Beck Depressions Inventory (BDI) have been used in many clincal trials but has not been implemented into clinical routine [36-38].

SF-36: The SF-36 is a generic questionnaire addressing aspects of health in the domains of physical functioning, physical and emotional roles, bodily pain, general health, vitality, social functioning, and mental health [22]. The summary scores range from 0 to 100 with higher scores indicate better levels of function and/or better health. The main components of SF-36 are physical (physical component score, PCS) and mental component summary (MCS) scores for which a standardized sample is available allowing to compare disease-specific values with the general population. Many studies consistently showed that in patients with axSpA both the physical (PCS) and mental (MCS) health is limited but tend to improve when initiating effective treatment regimens [5,39]. A $\geq 3$ point increase in the SF-36 PCS for an individual patient is considered the minimal clinically important improvement [40].

EQ-5D: The EQ-5D-5L provides societal preferences for health states (health utility) based on 5 dimensions of health: mobility, self-care, usual activities, pain/discomfort, and anxiety/depression [25]. Each dimension has 5 levels: no problems, slight problems, moderate problems, severe problems, and extreme problems. The generic questionnaire is based on a preference-based method of HRQoL and can be used in clinical and health economic studies. In comparison to preference values of country-specific samples of the general population, the individual health status of the axSpA patient can be calculated. The EQ-5D value indicates the health status of the patient from 0 (very poor health) to 1 (best possible health). In many studies, the EQ-5D value is given for axSpA patients with values between 0.6 and 0.8. In addition to the 5 domains, the patient indicates his level of health on a visual analogue scale from 0 to 100 . Using an online calculation template, the patient's answers can be converted into an index value (https://euroqol.org/ eq-5d-instruments/eq-5d-5l-about/valuation-standardvalue-sets/crosswalk-index-value-calculator/). The EQ-5D index can be used in Quality Adjusted Life Years assessments and as a stand-alone index in health economic evaluations.

ASAS HI: The ASAS HI was developed by ASAS in order to cover the entire spectrum of possible limitations of health in patients with SpA [23]. This health index was developed on the basis of the ICF core set for AS in order to record the limitations of functioning specific for patients with axSpA [35]. The ASAS HI contains 17 dichotomous items that represent categories such as pain, emotional function, sleep, sexual function, mobility, independence, social life and working life. The sum score of 
the ASAS Health Index is between 0 (good functioning) and 17 points (poor functioning). The disease-specific questionnaire was developed for use in clincial trials. To differentiate between poor, moderate and good functional ability, threshold values were determined (good functional ability $<5$ points; poor functional ability $\geq 12$ points). The ASAS HI is mainly collected in studies, its use in daily routine is not known.

\section{3) Work productivity}

Restrictions in working life represent a multifaceted problem and impairments are prevalent in many patients [41]. Limitations can be recorded with various questionnaires of which the Work Productivity and Activity Impairment Questionnaire (WPAI) is most often used [26]. The WPAI consists of 6 questions on current employment, number of hours missed due to SpA, number of hours missed for other reasons, number of hours actually worked and degree of impairment in work/leisure. Reporting time frame is the last 7 days before answering the questionnaire. This self-reort questionnaire consists of 4 domains: absenteeism, presenteism, work impairment and activity impairment. The WPAI score is calculated as a percentage for all domains, with a high percentage being a major limitation. The values in axSpA patients for the category absenteism vary between 2 and approx. $10 \%$, those for the category presenteism and work satisfaction between $20 \%$ and $40 \%$ and those for the category impairment of everyday activity between $20 \%$ and $50 \%$. WPAI is used in both clinical and epidemiological studies. In the British Biologicaregister it could be shown that after initiation of a biologika a reduction of the work incapacity and a decrease of the work and everyday life impairment of up to $17 \%$ could be achieved [27]. For each WPAI outcome, an improvement of $\geq 7$ points from baseline for an individual patient is considered the minimal clincially improtant improvement [42].

\section{4) Assessment of physical performance}

As explained above, physical function, as a patient-reported outcome, is often assessed by the BASFI questionnaire or by physical examination as range of movement. However, those assessments do not necessarily correlate with the current performance of an individual patient. Assessment of performance tests are standard of care in other diseases such as pulmonary diseases including pulmonary arterial hypertension in systemic sclerosis, in which, for example, measurement of gait speed is used for clinical decision making. Physical performance can be assessed as a single task such as grip strength or as a generic compound measure. Generic performance measures are widely used (e.g., short physical performance battery, SPPB) to assess physical performance more objectively [43]. The SPPB has been developed for geriatric patients and can discriminate patients with high and low fall risk by testing three complex tasks (chair rising test, balance test and gait speed). Recent research in axSpA has paid some attention to measure physical performance in axSpA patients as well. In a monocentric, prospective and cross-sectional study that impairment in performance is frequent in patients with axSpA [44]. Although tests were done in a quite young axSpA cohort (mean age 44.3 [12.5] year) an impairment in $\geq 1$ performance test was seen in 87 patients (43.5\%). A disease-specific performance test is available for patients with axSpA as well. The ankylosing spondylitis performance index (ASPI) is a performance-based measure for physical functioning, which has been validated in Dutch patients with $\mathrm{r}$-axSpA. The ASPI measures the time to perform three daily activities (bending to pick up 6 pencils from the floor, putting on socks and standing up from the floor) $[45,46]$. The ASPI has previously shown an adequate to excellent (intraclass correlation coefficient $>0.70$ ) intra-rater test-retest reliability, good responsiveness (after TNFi initiation) and successfully measures different aspects of function compared to the BASFI questionnaire $[47,48]$.

\section{CONCLUSION}

A large number of outcome parameters exist for both clinical routine and clinical studies. Instruments are used depending on the disease manifestation and its severity of axSpA. In clinical routine, the use of instruments is limited mainly to assessment of disease activity and physical functioning. In clinical trials, a large number of domains can be recorded in a standardized manner, depending on the focus of the study.

\section{CONFLICT OF INTEREST}

No potential conflict of interest relevant to this article was reported.

\section{AUTHOR CONTRIBUTIONS}

All authors had access to the literature and wrote and 
checked the manuscript.

\section{REFERENCES}

1. Sieper J, Poddubnyy D. Axial spondyloarthritis. Lancet 2017;390:73-84.

2. Boel A, Molto A, van der Heijde D, Ciurea A, Dougados M, Gensler LS, et al. Do patients with axial spondyloarthritis with radiographic sacroiliitis fulfil both the modified New York criteria and the ASAS axial spondyloarthritis criteria? Results from eight cohorts. Ann Rheum Dis 2019;78: 1545-9.

3. Rudwaleit M, van der Heijde D, Landewé R, Listing J, Akkoc $\mathrm{N}$, Brandt J, et al. The development of Assessment of SpondyloArthritis international Society classification criteria for axial spondyloarthritis (part II): validation and final selection. Ann Rheum Dis 2009;68:777-83.

4. van der Linden S, Valkenburg HA, Cats A. Evaluation of diagnostic criteria for ankylosing spondylitis. A proposal for modification of the New York criteria. Arthritis Rheum 1984;27:361-8.

5. Kiltz U, Baraliakos X, Karakostas P, Igelmann M, Kalthoff L, Klink C, et al. Do patients with non-radiographic axial spondylarthritis differ from patients with ankylosing spondylitis? Arthritis Care Res (Hoboken) 2012;64:1415-22.

6. Kiltz U, Baraliakos X, Karakostas P, Igelmann M, Kalthoff L, Klink C, et al. The degree of spinal inflammation is similar in patients with axial spondyloarthritis who report high or low levels of disease activity: a cohort study. Ann Rheum Dis 2012;71:1207-11.

7. Ward MM. Health-related quality of life in ankylosing spondylitis: a survey of 175 patients. Arthritis Care Res 1999;12:247-55.

8. Salaffi F, Carotti M, Gasparini S, Intorcia M, Grassi W. The health-related quality of life in rheumatoid arthritis, ankylosing spondylitis, and psoriatic arthritis: a comparison with a selected sample of healthy people. Health Qual Life Outcomes 2009;7:25.

9. Ward MM. Predictors of the progression of functional disability in patients with ankylosing spondylitis. J Rheumatol 2002;29:1420-25.

10. Bedaiwi M, Sari I, Thavaneswaran A, Ayearst R, Haroon N, Inman RD. Fatigue in ankylosing spondylitis and nonradiographic axial spondyloarthritis: analysis from a longitudinal observation cohort. J Rheumatol 2015;42:2354-60.

11. Kilic G, Kilic E, Ozgocmen S. Relationship between psychiatric status, self-reported outcome measures, and clinical parameters in axial spondyloarthritis. Medicine (Baltimore) 2014;93:e337.

12. Garrido-Cumbrera M, Delgado-Domínguez CJ, Gálvez-Ruiz D, Mur CB, Navarro-Compán V; Atlas Working Group. The effect of axial spondyloarthritis on mental health: results from the atlas. J Rheumatol 2019;46:1284-9.

13. Boonen A, Chorus A, Miedema H, van der Heijde D, van der Tempel H, van der Linden S. Employment, work disability, and work days lost in patients with ankylosing spondylitis: a cross sectional study of Dutch patients. Ann Rheum Dis 2001;60:353-8.

14. Zink A, Braun J, Listing J, Wollenhaupt J. Disability and handicap in rheumatoid arthritis and ankylosing spondyli- tis--results from the German rheumatological database. German Collaborative Arthritis Centers. J Rheumatol 2000; 27:613-22.

15. Haglund E, Bremander A, Bergman S, Jacobsson LT, Petersson IF. Work productivity in a population-based cohort of patients with spondyloarthritis. Rheumatology (Oxford) 2013;52:1708-14.

16. Chorus AM, Miedema HS, Boonen A, Van Der Linden S. Quality of life and work in patients with rheumatoid arthritis and ankylosing spondylitis of working age. Ann Rheum Dis 2003;62:1178-84.

17. Dagfinrud H, Mengshoel AM, Hagen KB, Loge JH, Kvien TK. Health status of patients with ankylosing spondylitis: a comparison with the general population. Ann Rheum Dis 2004;63:1605-10.

18. Anderson JJ, Baron G, van der Heijde D, Felson DT, Dougados M. Ankylosing spondylitis assessment group preliminary definition of short-term improvement in ankylosing spondylitis. Arthritis Rheum 2001;44:1876-86.

19. Kiltz U, van der Heijde D. Health-related quality of life in patients with rheumatoid arthritis and in patients with ankylosing spondylitis. Clin Exp Rheumatol 2009;27(4 Suppl 55):S108-11.

20. Jones SD, Steiner A, Garrett SL, Calin A. The Bath Ankylosing Spondylitis Patient Global Score (BAS-G). Br J Rheumatol 1996;35:66-71.

21. Garrett S, Jenkinson T, Kennedy LG, Whitelock H, Gaisford $\mathrm{P}$, Calin A. A new approach to defining disease status in ankylosing spondylitis: the Bath Ankylosing Spondylitis Disease Activity Index. J Rheumatol 1994;21:2286-91.

22. Braun J, Brandt J, Listing J, Zink A, Alten R, Golder W, et al. Treatment of active ankylosing spondylitis with infliximab: a randomised controlled multicentre trial. Lancet 2002;359: 1187-93.

23. Song IH, Rudwaleit M, Listing J, Sieper J. Comparison of the Bath Ankylosing Spondylitis Disease Activity Index and a modified version of the index in assessing disease activity in patients with ankylosing spondylitis without peripheral manifestations. Ann Rheum Dis 2009;68:1701-7.

24. Essers I, Boonen A, Busch M, van der Heijde D, Keszei AP, Landewé $\mathrm{R}$, et al. Fluctuations in patient reported disease activity, pain and global being in patients with ankylosing spondylitis. Rheumatology (Oxford) 2016;55:2014-22.

25. Santos-Faria D, Dougados M, Gossec L, Perrot S, Moltó A. Evaluation of the performance of extreme patient-reported outcomes as surrogate markers for fibromyalgia in axial spondyloarthritis. Rheumatol Int 2019;39:141-6.

26. Baraliakos X, Regel A, Kiltz U, Menne HJ, Dybowski F, Igelmann $\mathrm{M}$, et al. Patients with fibromyalgia rarely fulfil classification criteria for axial spondyloarthritis. Rheumatology (Oxford) 2018;57:1541-7.

27. Rudwaleit M, Listing J, Brandt J, Braun J, Sieper J. Prediction of a major clinical response (BASDAI 50) to tumour necrosis factor alpha blockers in ankylosing spondylitis. Ann Rheum Dis 2004;63:665-70.

28. Lukas C, Landewé R, Sieper J, Dougados M, Davis J, Braun $\mathrm{J}$, et al.; Assessment of SpondyloArthritis international Society. Development of an ASAS-endorsed disease activity score (ASDAS) in patients with ankylosing spondylitis. Ann Rheum Dis 2009;68:18-24.

29. Machado P, Landewé R, Lie E, Kvien TK, Braun J, Baker D, 
et al.; Assessment of SpondyloArthritis international Society. Ankylosing Spondylitis Disease Activity Score (ASDAS): defining cut-off values for disease activity states and improvement scores. Ann Rheum Dis 2011;70:47-53.

30. Molto A, Gossec L, Meghnathi B, Landewé RBM, van der Heijde D, Atagunduz P, et al.; ASAS-FLARE study group. An Assessment in SpondyloArthritis International Society (ASAS)-endorsed definition of clinically important worsening in axial spondyloarthritis based on ASDAS. Ann Rheum Dis 2018;77:124-7.

31. Ramiro S, van Tubergen A, Stolwijk C, van der Heijde D, Royston P, Landewé R. Reference intervals of spinal mobility measures in normal individuals: the MOBILITY study. Ann Rheum Dis 2015;74:1218-24.

32. Jenkinson TR, Mallorie PA, Whitelock HC, Kennedy LG, Garrett SL, Calin A. Defining spinal mobility in ankylosing spondylitis (AS). The Bath AS Metrology Index. J Rheumatol 1994;21:1694-8.

33. Calin A, Garrett S, Whitelock H, Kennedy LG, O'Hea J, Mallorie $\mathrm{P}$, et al. A new approach to defining functional ability in ankylosing spondylitis: the development of the Bath Ankylosing Spondylitis Functional Index. J Rheumatol 1994;21:2281-5.

34. Cieza A, Hilfiker R, Boonen A, van der Heijde D, Braun J, Stucki G. Towards an ICF-based clinical measure of functioning in people with ankylosing spondylitis: a methodological exploration. Disabil Rehabil 2009;31:528-37.

35. Boonen A, Braun J, van der Horst Bruinsma IE, Huang F, Maksymowych W, Kostanjsek N, et al. ASAS/WHO ICF Core Sets for ankylosing spondylitis (AS): how to classify the impact of AS on functioning and health. Ann Rheum Dis 2010;69:102-7.

36. Zigmond AS, Snaith RP. The hospital anxiety and depression scale. Acta Psychiatr Scand 1983;67:361-70.

37. Gilbody S, Richards D, Brealey S, Hewitt C. Screening for depression in medical settings with the Patient Health Questionnaire (PHQ): a diagnostic meta-analysis. J Gen Intern Med 2007;22:1596-602.

38. Smarr KL, Keefer AL. Measures of depression and depressive symptoms: Beck Depression Inventory-II (BDI-II), Center for Epidemiologic Studies Depression Scale (CES-D), Geriatric Depression Scale (GDS), Hospital Anxiety and Depression Scale (HADS), and Patient Health Questionnaire-9 (PHQ-9). Arthritis Care Res (Hoboken) 2011;63 Suppl 11:S454-66.

39. van der Heijde D, Deodhar A, Braun J, Mack M, Hsu B, Gathany TA, et al.; GO-RAISE investigators. The effect of golimumab therapy on disease activity and health-related quality of life in patients with ankylosing spondylitis: 2-year results of the GO-RAISE trial. J Rheumatol 2014;41: 1095-103.

40. Davis JC Jr, Revicki D, van der Heijde DM, Rentz AM, Wong $\mathrm{RL}$, Kupper $\mathrm{H}$, et al. Health-related quality of life outcomes in patients with active ankylosing spondylitis treated with adalimumab: results from a randomized controlled study. Arthritis Rheum 2007;57:1050-7.

41. Shim J, Jones GT, Pathan EMI, Macfarlane GJ. Impact of biological therapy on work outcomes in patients with axial spondyloarthritis: results from the British Society for Rheumatology Biologics Register (BSRBR-AS) and metaanalysis. Ann Rheum Dis 2018;77:1578-84.

42. Reilly MC, Gooch KL, Wong RL, Kupper H, van der Heijde D. Validity, reliability and responsiveness of the Work Productivity and Activity Impairment Questionnaire in ankylosing spondylitis. Rheumatology (Oxford) 2010;49:812-9.

43. Cawthon PM, Fullman RL, Marshall L, Mackey DC, Fink HA, Cauley JA, et al.; Osteoporotic Fractures in Men (MrOS) Research Group. Physical performance and risk of hip fractures in older men. J Bone Miner Res 2008;23: 1037-44

44. Kiltz U, Ahomaa E, Bühring B, Baraliakos X, Braun J. Clinically relevant deficits in performance tests in patients with Axial Spondyloarthritis(axSpA) - collecting questionnaires is insufficient. Arthritis \& Rheum 2019;71 Suppl 10:1820.

45. van Weely SF, van Denderen CJ, van der Horst-Bruinsma IE, Nurmohamed MT, Dijkmans BA, Dekker J, et al. Reproducibility of performance measures of physical function based on the BASFI, in ankylosing spondylitis. Rheumatology (Oxford) 2009;48:1254-60.

46. van Weely SF, van Denderen JC, Steultjens MP, Nurmohamed MT, Dijkmans BA, Dekker J, et al. What do we miss? ASAS non-responders on anti-TNF therapy show improvement in performance-based physical function. Rheumatology (Oxford) 2013;52:1884-9.

47. van Weely SF, van Denderen JC, Steultjens MP, van der Leeden M, Nurmohamed MT, Dekker J, et al. Moving instead of asking? Performance-based tests and BASFI-questionnaire measure different aspects of physical function in ankylosing spondylitis. Arthritis Res Ther 2012;14:R52.

48. van Weely SF, Dekker J, Steultjens MP, van Denderen JC, Nurmohamed MT, Dijkmans BA, et al. Objective evaluation of physical functioning after tumor necrosis factor inhibitory therapy in patients with ankylosing spondylitis: a selection of 3 feasible performance-based tests. J Rheumatol 2015;42:623-9. 